\title{
OPTIMIZATION OF ORGANIC DYE (5MSA) ON THE EFFICIENCY OF DYE-SENSITIZED SOLAR CELLS (DSSC)
}

\section{Ragasudha G}

Department of Physics, D G Government Arts College, Mayiladuthurai, Affiliated with Bharathidasan University, Tamilnadu, India

\section{Idamalarselvi $R^{*}$}

Department of Physics, D G Government Arts College, Mayiladuthurai, Affiliated with Bharathidasan University, Tamilnadu, India

\section{Priscilla R}

Postgraduate Department of Physics, A.D.M. College for Women (Autonomous), Nagapattinam, Tamilnadu, India.

\section{Ramachandra Raja C}

Research and Postgraduate Department of Physics, Government Arts College (Autonomous), Kumbakonam, Tamilnadu, India.

*Corresponding Author

\begin{abstract}
The impartial of this study is to investigate the absorbance and electrochemical properties of organic dye 5-Methyl salicylaldehyde-Aniline (5MSA).To the best of our knowledge we have the first time produced the biodegradable organic dyes with a new band gap of small molecule 5MSA by slow evaporation method. The absorbance and electrochemical properties were tested by Ultraviolet-visible (UV-Vis),Fourier transform infrared (FTIR)spectroscopy, Photoluminescence and cyclic voltammetry $(C V)$. The composition, particle size and structure of this dye were characterized by FESEM and XRD analysis. The results shows that the absorbance spectrum of dyes was at a wavelength from 200-500 nm. The dye also have $C=N, C-N$ and $O-H$ which important for anchoring in semiconductors. Moreover, the level energy of highest occupied molecular orbital and that of lowest unoccupied molecular orbital from organic dye 5-Methylsalicylaldehyde-aniline were $-5.142 \mathrm{eV}$ and $-3.572 \mathrm{eV}$ respectively. The findings show that the organic dye 5-Methylsalicylaldehyde-aniline dye may be a promising properties for DSSC.
\end{abstract}


Key words: DSSC, 5-Methylsalicylaldehyde-aniline, Cyclic Voltammetry, HOMO, LUMO, Photoluminescence and UV Spectroscopy

Cite this Article: Ragasudha G, Idamalarselvi R, Priscilla R and Ramachandra Raja C, Optimization of Organic Dye (5MSA) on the Efficiency of Dye-Sensitized Solar Cells (DSSC), International Journal of Management, 11(12), 2020, pp 1931-1938.

http://iaeme.com/Home/issue/IJM?Volume=11\&Issue=12

\section{INTRODUCTION}

DSSC have involved worldwide consideration, because of their promising light gathering to energy alteration efficiency and environmental field. The high energy alteration efficiency of DSSC is proficient complete the use of highly porous semiconductor films coated with dye sensitizer as the working electrode. This was developed by O'Regan and Gratzel [1]. A extraordinary development in the use of biodegradable organic dyes for DSSC was recently concerned the consideration of researchers and such materials have proved to be promising candidates for photo chemical and photo therapeutic applications.

DSSC can convert light into current. In DSSC, the dye acts as a sensitizer that absorbs light on visible light areas and injects electrons. Sensitizers in DSSC are divided into two major groups' namely complex metal (synthetic dyes) and organic or natural dyes.

Fig.1 shows the chemical scheme of 5MSA Dye. 5MSAis an important class of high performance dyes, which are easily process able and display good electrochemical and optical -oxidation stability. In this work the performance of MSA metal free dye in DSSC is analyzed.

It is generally used in various application such as Supercapacitors [4,5], Field Emission[6], Sensor[7] and DSSC[8-12].

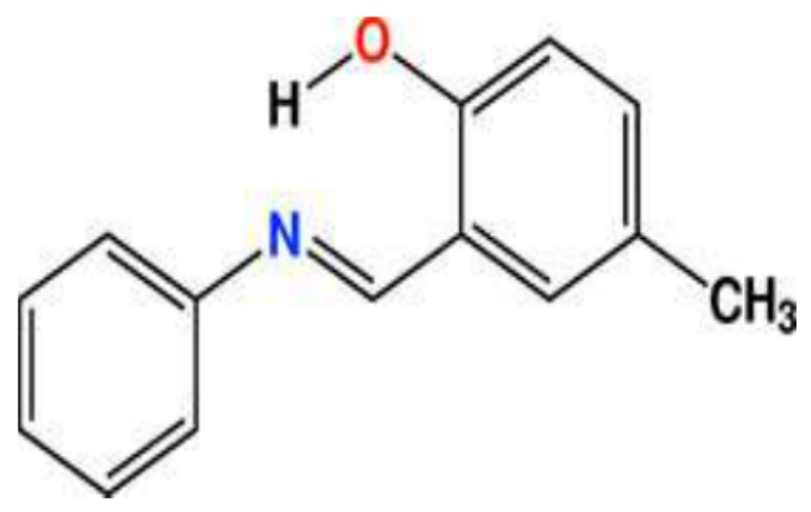

Figure 1 Chemical Structure of 5MSA dye

\section{EXPERIMENTAL AND METHODS}

\section{Materials}

5-Methyl salicylaldehyde, aniline used were Merck products. The Ethyl acetate was used to prepare the solution.

\section{Synthesis of Organic dye}

A liquid metallurgy route has been adopted to fabricate the Dye.

5 Methyl Salicylaldehyde and aniline were subjected to solution at continuously stirrered 1 $\mathrm{hr}$ to form the dye. The prepared solution to deep yellow reveals the formation of the dye. 


\section{Characterization of Organic dye}

In this study organic dye will be subjected to several tests as follows:

- UV-Vis is used for light absorption test and light intensity on the dye properties,

- Photoluminescence is used for excitation wavelength on the dye,

- FTIR is used to identify the chemical bonding in dye,

- Cyclic voltammetry is used to determine the potential energyof reduction( $\left.\mathrm{E}_{\text {reduction }}\right)$ and oxidation potential energy ( $\left.E_{\text {oxidation }}\right)$.

- FESEM and XRD were analyzed chemical structure and determined the particle size.

\section{RESULTS AND DISCUSSION}

\subsection{UV-Visible spectra of Dye}

Fig.2 The uptake of light for organic dye 5-Methylsalicylaldehyde-aniline. Visible light absorption area for 5MSA dye is at a wavelength of 190-1100 $\mathrm{nm}$ (UV- DRS Spectrometer)

We calculated efficiency at different wavelength, finally taken bandgap $2.39 \mathrm{eV}$ at $520 \mathrm{~nm}$. Because, if energy bandgap value is $<3 \mathrm{eV}$, it having a semiconducting properties.

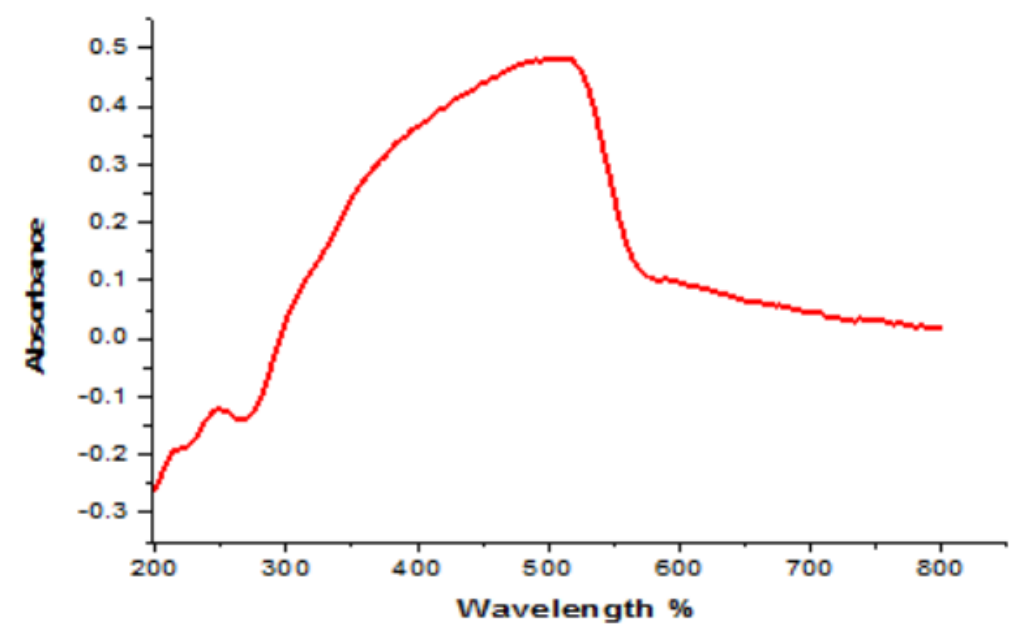

Figure 2 UV- Visible spectrum of 5MSA Dye

\subsection{FT-IR Spectral Analysis}

\subsubsection{FT-IR Measurements}

Fig. 3 shows the FTIR spectrum of 5MSA dyes. In 5MSA dyes there are $\mathrm{C}=\mathrm{N}, \mathrm{C}-\mathrm{N}$ and $\mathrm{O}-\mathrm{H}$ groups where the absorption peak occurs in the area of $1620.77 \mathrm{~cm}^{-1} 1360.64 \mathrm{~cm}^{-1}$ and $3443.06 \mathrm{~cm}^{-1}$. 


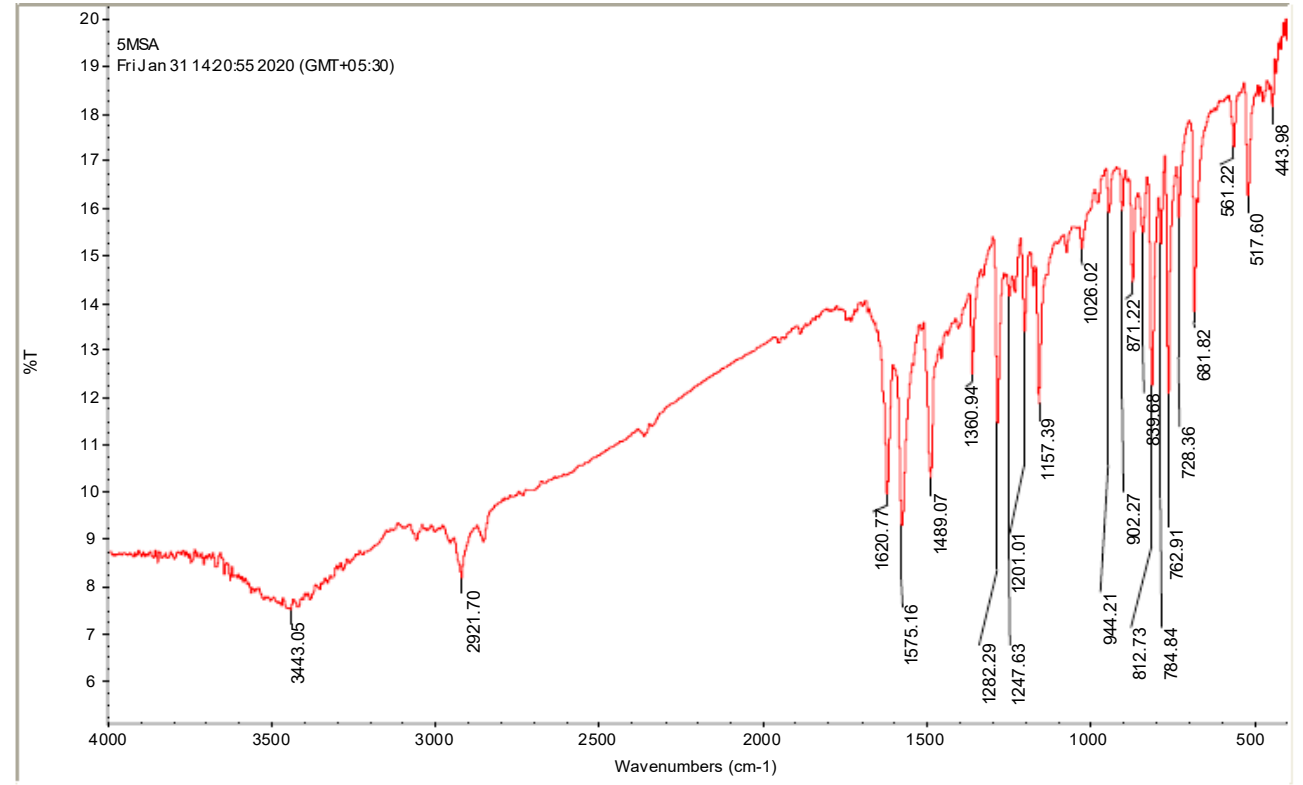

Figure 3 FT-IR Spectrum of 5MSA Dye

\subsection{Cyclic Voltammetry}

\subsubsection{Cyclic Voltammetry Measurements}

Fig.4 shows the Cyclic voltammetry (Princeton applied research-Versa STAT MC)is used to identify level energy in organic dyes and $\mathrm{CV}$ is performed by cycling the potential of a working electrode measuring the resulting current. The energy level consists of HOMO and LUMO energy. HOMO (Highest occupied molecular orbital) is an outer orbit theat has a high molecular energy level acts as an electron donor. While LUMO (Lowest unoccupied molecular orbital) is the deepest orbit that has a vacuum electrons that act as a acceptor or receiver of electrons from HOMO energy. When choosing organic dyes used for semiconductor dyes in DSSC, this is very important because to know the energy level HOMO, LUMO and bandgap obtained from the energy difference HOMO and LUMO. In above table HOMO energy for 5MSA dye is $-5.142 \mathrm{eV}$, energy LUMO $-3.572 \mathrm{eV}$. Therefore when LUMO energy more higher from the HOMO energy is more easily to the electron dye from the HOMO energy jump to the LUMO energy. The HOMO energy level of the dye must be more positive than the redox potential of the electrolyte. Even some researchers suggest to make the energy difference between HOMO dyes with redox potential $0.2-0.3 \mathrm{eV}$ so that the regeneration of the dye from the electrolyte goes efficiently. Likewise, the LUMO energy level of the dye must be more negative than the potential energy of the conduction band of the semiconductor in order for the electron injection toproceed properly. Therefore, the HOMO and LUMO energy level cannot be detected only from the dye but also must be adjust according to the energy level of the semiconductor and the electrolyte.

Table 1 Oxidation energy, Energy reduction, HOMO and LUMO measuring with cyclic voltammetry

\begin{tabular}{|c|c|c|c|c|c|}
\hline Dye & $\mathbf{E}_{\mathbf{0 x}}(\mathbf{V})$ & $\mathbf{E}_{\text {red }}(\mathbf{V})$ & $\mathbf{E}_{\text {номо }}{ }^{\mathbf{a}}(\mathbf{e V})$ & $\mathbf{E}_{\text {LUMo }}{ }^{\mathbf{b}}(\mathbf{e V})$ & $\mathbf{E}_{\text {Energygap }}{ }^{\mathbf{c}}(\mathbf{e V})$ \\
\hline $5 \mathrm{MSA}$ & 0.742 & -0.828 & -5.142 & -3.572 & 1.57 \\
\hline
\end{tabular}

$$
\begin{aligned}
& \mathrm{E}_{\mathrm{HOMO}}=-\mathrm{e}\left[\mathrm{E}_{\mathrm{Ox}}+4.4\right] \\
& \mathrm{E}_{\text {LUMO }}=-\mathrm{e}\left[\mathrm{E}_{\mathrm{red}}+4.4\right] \\
& \mathrm{E}_{\text {Energygap }}=\left[\mathrm{E}_{\text {LUMO }}-\mathrm{E}_{\text {LUMO }}\right]
\end{aligned}
$$




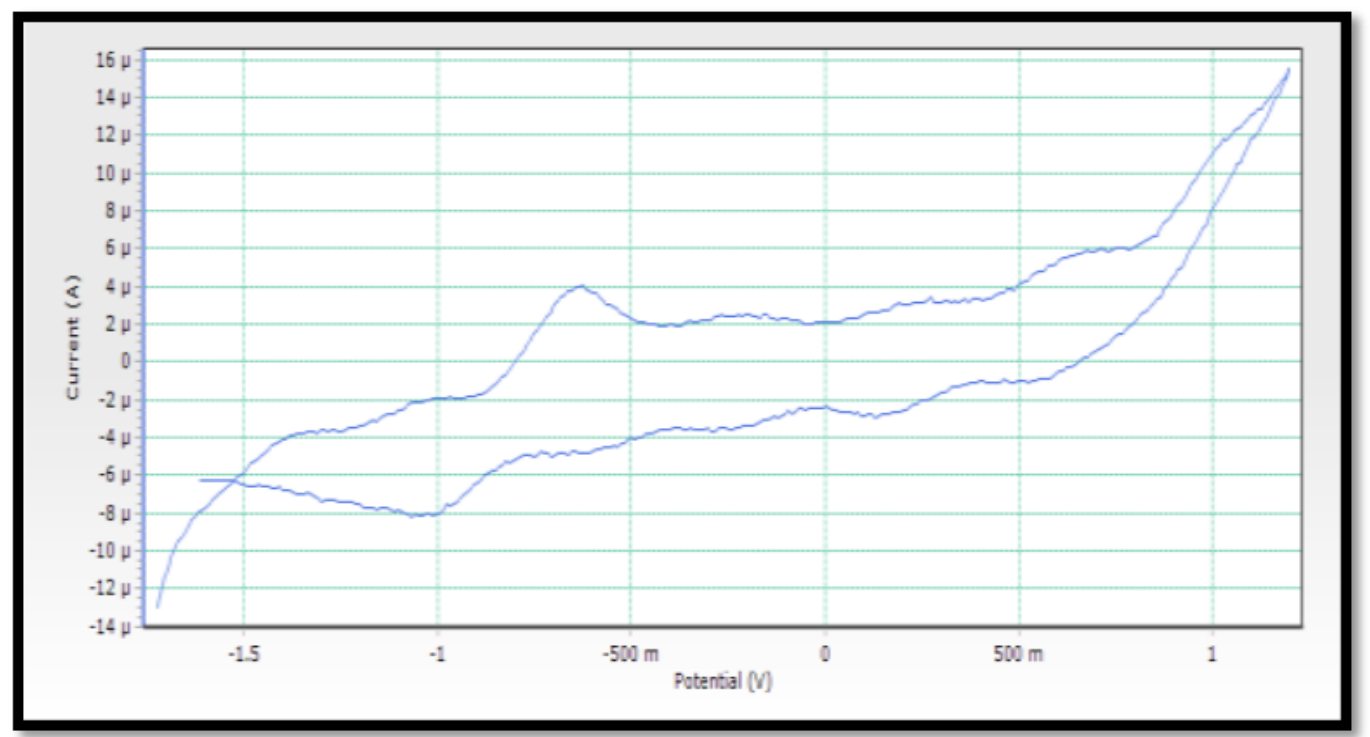

Figure 4 Cyclic voltammetry of 5MSA Dye

\subsection{Scanning Electron Microscopy}

\subsubsection{SEM Image of MSA Dye}

The particles appeared as aggregates of tiny particles. They were particles of both nano and bulk dimensions and the major constituents were nano dimensions. Average diameter of the particles was equal to $2 \mu \mathrm{m}$. In all the microphotographs of fractured surfaces, single and double black arrows indicate some of the inter granular /intra granular pores, whenever they appear. It is noteworthy to mention that in some micro photographs, very white patches appear at a few isolated places of fractured surface. These patches are not the same as indicated by the formation of composite phase. Fig. 5 incorporates the microphotographs of nanocomposite MSA. There is no major difference in grain morphology of these sample. Many grains retain their initial identity (i.e) grain surfaces are largely spherical and sharp edges / corners are absent. Only a small number of inter - granular pores can be seen in the photographs.
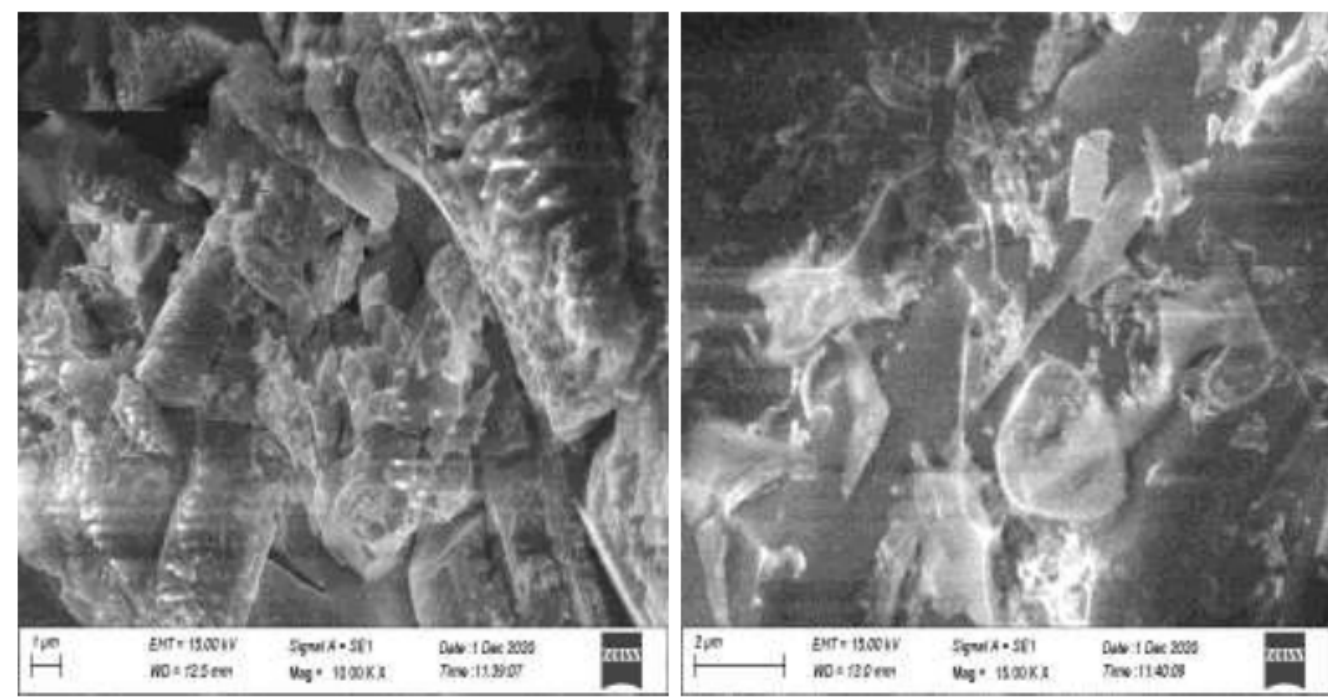

Figure 5 SEM images of 5MSA Dye 


\subsection{X-Ray Diffraction}

\subsubsection{XRD Analysis}

Fig.6 shows the XRD patterns (PANalytical X'Pert PRO Powder XRD )of glass substrate and $5 \mathrm{MS}$ dye film with aniline. It shows that the 5MSA dye display like peaks at $2 \theta$ values $16.9^{\circ}$, $19.5^{\circ}$ and $19.8^{\circ}$ can be assigned to (002),(110) and (032). Mean grain size (d) was calculated by using Debye-scherer formula $\mathrm{d}=0.9$, where $\mathrm{d}$ is mean grain size, $\lambda$ the wavelength of $\mathrm{x}$-rays used $(1.540 \AA$ ), $\theta$ is the angle of diffraction and $\beta$-FWHM (Full width Half Maximum) of observes peaks by using this formula we calculate average grain size as $8.311 \mathrm{~nm}$. The XRD patterns have only one intense peak suggesting the noticeable disordered nature of the system, the same is also confirmed from the SEM micrographs. Structural information suggests simple or multifaceted defects such as defect centre, micro voids, imperfections, cracks, etc may be present in the composite. These defects originate the defect states like shallow and deep states which may act as donor or acceptors. These states may also lead to the probable formation of dipoles, which are responsible for the semiconductor behavior.

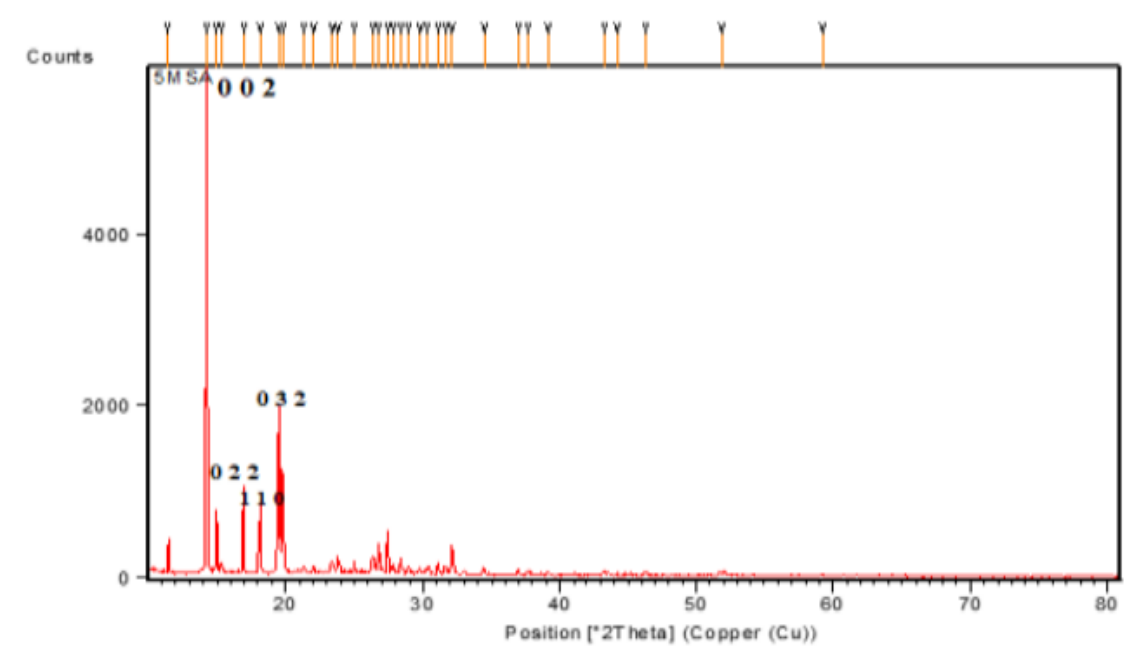

Figure 6 XRD Patterns of 5MSA dye

\subsection{Photoluminescence}

\subsubsection{PL Analysis}

Fig. 7 shows the Excitation wavelength of 5MSA Dye. The peak of 5MSA dye Exitation lies at a wavelength of $363 \mathrm{~nm}$. While the absorption intensity is 64.12 a.u.

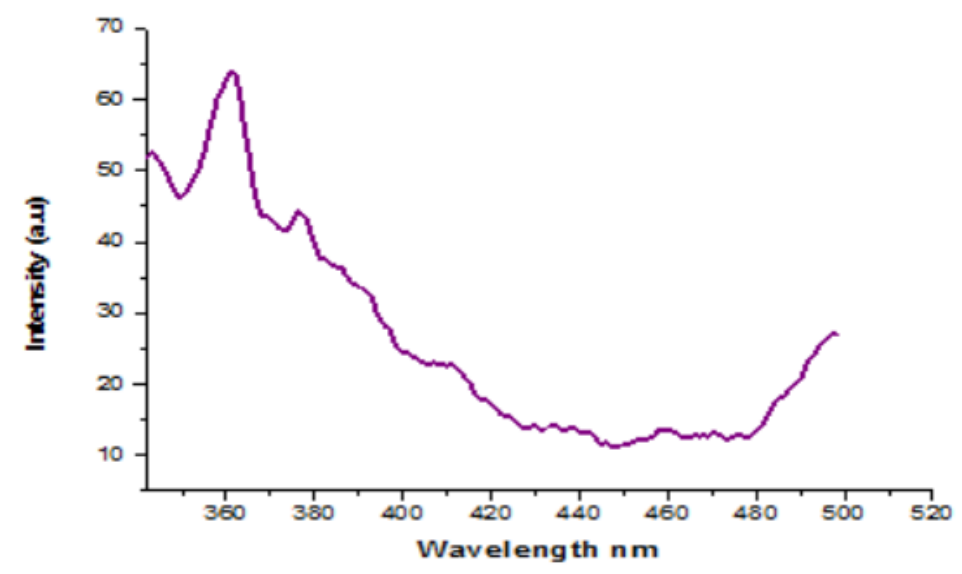

Figure 6 Photoluminescence spectrum of 5MSA dye 


\section{CONCLUSION}

To the best of our knowledge we have for the first time produced biodegradable organic dyes 5MSA by slow evaporation method. Based on the analysis of structures, Morphology, spectral and Electro chemical properties of 5MSA, enlarged the distance between electron donor group and semiconductor surface, and decreased the time scale of the electron injection rate, resulted in giving lower conversion efficiency. This indicates conjugate bridge in dye sensitizer is very important to improve the performance of DSSC. From the FTIR (Fourier Transform infrared spectroscopy) testing of 5MSA organic dye there are $\mathrm{C}=\mathrm{N}, \mathrm{C}-\mathrm{N}$ and $\mathrm{O}-\mathrm{H}$ groups where the absorption peak occurs in the area of $1620.77 \mathrm{~cm}^{-1} 1360.64 \mathrm{~cm}^{-1}$ and $3443.06 \mathrm{~cm}^{-1}$. While to know the energy level of 5NSA dye done by $\mathrm{CV}$ test (cyclic voltammetry) results as follows: $\mathrm{E}_{\text {reduction }}=-0.828 \mathrm{~V}, \mathrm{E}_{\mathrm{LUMO}}=-3.572 \mathrm{eV}, \mathrm{E}_{\text {oxidation }}=0.742 \mathrm{~V}$, $\mathrm{E}_{\mathrm{HOMO}}=-5.142 \mathrm{eV}$.

\section{ACKNOWLEDGEMENT}

The authors gratefully acknowledge Alagappa University, Karaikudi for XRD and Photoluminescence, St. Joseph College, Trichy for UV Vis NIR, FT-IR and Cyclic Voltammetry and International Research center Sathyabama University for SEM analysis.

\section{AUTHOR INFORMATION}

\section{Corresponding Author}

\section{Idamalarselvi R}

\section{Present Address}

DG Government Arts College, Mayiladuthurai 609 001,

Tamilnadu, India.

\section{*Notes}

The authors declare no competing financial interest.

\section{REFERENCES}

[1] B.O'Regan and M.Gratzel, "Electrochemically deposited polypyrrole for dye sensitized solar cellcounter electrode," Nature, vol, 353, no.6346, pp. 737-740, 1991.

[2] L. X. Wang, X. G. Li, and Y. L. Yang, "Preparation, properties and applications of polypyrroles,"Reactive and Functional Polymers, vol. 47, no. 2, pp. 125-139, 2001.

[3] S. Mokrane, L. Makhloufi, and N. Alonso-Vante, "Electrochemistry of platinum nanoparticles supported in polypyrrole (PPy)/C composite materials," Journal of Solid State Electrochemistry, vol.12, no. 5, pp. 569-574, 2008.

[4] J. Wang, Y. Xu, X. Chen, and X. Du, "Electrochemical supercapacitor electrode material based onpoly(3,4-ethylenedioxythiophene)/ polypyrrole composite," Journal of Power Sources, vol. 163, no. 2,pp. 1120-1125, 2007.

[5] R. K. Sharma, A. C. Rastogi, and S. B. Desu, "Manganese oxide embedded polypyrrolenano composites for electrochemical supercapacitor," Electrochimica Acta, vol. 53, no. 26, pp. 7690-7695, 2008.

[6] R. K. Sharma, A. C. Rastogi, and S. B. Desu, "Pulse polymerized polypyrrole electrodes for highenergy density electrochemical supercapacitor," Electrochemistry Communications, vol. 10, no. 2, pp.268-272, 2008. 
Optimization of Organic Dye (5MSA) on the Efficiency of Dye-Sensitized Solar Cells (DSSC)

[7] B.H. Kim, D.H. Park, J. Joo, S. G. Yu, and S. H. Lee, "Synthesis, characteristics, and field emission of doped and de-doped polypyrrole, polyaniline, poly(3,4-ethylenedioxythiophene) nanotubes and nanowires," Synthetic Metals, vol. 150, no. 3, pp. 279-284, 2005.

[8] A.Lim, N.T.R.N. Kumaran, A.L. Tan, Mirza, R.L.N. Chandrakanthi, M.I. Petra, L.C. Ming, G.K.R. Senadeera and P. Ekanayake, Spectrochim. Acta, Part A, 2015.138:p.596-602.

[9] A. Joshi, S. A. Gangal, and S. K. Gupta, "Ammonia sensing properties of polypyrrole thin films atroom temperature," Sensors and Actuators B, vol. 156, no. 2, pp. 938-942, 2011.

[10] J. Wu, Q. Li, L. Fan et al., "High-performance polypyrrole nanoparticles counter electrode for dyesensitized solar cells," Journal of Power Sources, vol. 181, no. 1, pp. 172-176, 2008.

[11] S. S. Jeon, C. Kim, J. Ko, and S. S. Im, "Spherical polypyrrole nanoparticles as a highly efficientcounter electrode for dyesensitizedsolar cells," Journal of Materials Chemistry, vol. 21, no. 22, pp. 8146-8151, 2011.

[12] T. Makris, V. Dracopoulos, T. Stergiopoulos, and P. Lianos, "A quasi solid-state dyesensitizedsolar cell made of polypyrrolecounter electrodes," Electrochimica Acta, vol. 56, no. 5, pp. 2004-2008, 201 